\title{
PREVALENCE OF PREHYPERTENSION AMONGST MEDICAL STUDENTS IN COASTAL KARNATAKA
}

Shobha S Shetty, Avinash Nayak

1. Associate Professor, Department of General Medicine, K.S. Hegde Medical Academy, Derlakatte, Mangalore.

2. Final MBBS Student. K.S. Hegde Medical Academy, Derlakatte, Mangalore

\section{CORRESPONDING AUTHOR}

Dr. Shobha S Shetty

Associate Professor, Dept. of General Medicine,

K. S. Hegde Medical Academy,

Derlakatte, Mangalore 575018

E-mail: shobhashetty22@gmail.com

Ph: 00919880008470.

ABSTRACT: AIMS: The main aims were to assess the incidence of prehypertension amongst the medical students in our institution with its correlation with increasing Body Mass Index(BMI) \& to see if there was any gender variation. MATERIALS \& METHODS: A total of 500 medical students consented to participate in this study, their BP reading were recorded after a demographic questionnaire to assess their socioeconomic status \& BMI. RESULTS: 277 students (55.4\%) were prehypertensives out of which 145(29\%) students had a high SBP \& 132(26.4\%) had high DBP. Amongst the 227 students, 33.2\% had both high SBP \& DBP out of which $64.1 \%$ were boys \& $35.9 \%$ were girls. In the entire study population, out of the 500 students, $25 \%$ of the boys \& $40 \%$ of the girls were overweight. CONCLUSIONS: In our centre we had more than $50 \%$ of the study group in the prehypertensive range with a higher incidence amongst boys \& about $40 \%$ of the girls were overweight. These figures are alarming \& hence a followup study is required for further analysis.

KEY WORDS: prehypertension, Karnataka, medical students, BMI

INTRODUCTION: Hypertension is an independent predictor of cardiovascular disease and cerebrovascular events affecting nearly a quarter of the adult population worldwide. The Seventh Report of the Joint National Committee on Prevention, Detection, Evaluation, and Treatment of High Blood Pressure (JNC7) defines hypertension as blood pressure $>140 / 90$ mmHg. Persons with blood pressure above optimal levels, but not clinical hypertension (systolic blood pressure of 120-139 mm Hg or diastolic blood pressure of 80-89 mm Hg), are defined as having "prehypertension". Subjects with pre-hypertension have a greater risk of developing hypertension later and risk of major cardiovascular events independent of other cardiovascular risk factors. Cardiovascular diseases contribute to atleast one third of deaths in India every year. Although hypertension has been well studied, there is dearth of data on the prevalence and risk factors for prehypertension in India.

With India emerging as an economically developed nation, the need of the hour is to focus research and data collection on urban as well as rural population. Studies targeting prehypertension would provide an estimate of the future magnitude of the problem and assist in developing strategies for control of hypertension and CVD (1). With growing urbanization, sociodevelopmental and life style changes from traditional to modern have lead to physical inactivity. Rising affluence has also modified the dietary pattern characterized by increased 
consumption of diets rich in fat, sugar and calories(4). The all cause mortality has also been shown to be $50 \%$ higher in the prehypertensive adults compared to the normotensive counterparts.

There are not many studies done in this part of the country which estimates the prevalence of this epidemic \& hence the study was planned. Drug therapy for prehypertension is not recommended for various reasons $(2,3)$. Our study population consisted of students enrolled in a medical school who were from similar socioeconomic status, dietary habits \& lifestyle. Early identification of prehypertension in this subgroup plays an important role in screening for metabolic syndrome and identifies modifiable factors required for proposing prevention strategies for prevention of cardiovascular accidents.

AIMS AND OBJECTIVES: To find out the incidence of prehypertension amongst medical students in our institution To show any possible correlation between high normal BP \& increasing BMI To assess any gender variation in the incidence of prehypertension

METHODS: This was a cross-sectional study done where 500 consenting students in the age group 18-22 years were randomly selected. The in-house ethical clearance was taken \& all standards were adhered to including a detailed informed consent to participate in the study. Their demographic data was collected which included their height, weight, habits. BMI was calculated using the standard international formula. To measure the blood pressure a mercury sphygmomanometer was used. We made sure there was no smoking or caffeine ingestion half an hour prior to the checking of their blood pressure. A cuff bladder encircling at least $80 \%$ of the arm circumference was applied to the nondominant arm. The disappearance of phase $\mathrm{V}$ Korotkoff sounds was taken as the diastolic reading. The mean of three readings, recorded 2 min apart, was taken. If these readings differed by more than $5 \mathrm{~mm} \mathrm{Hg}$, a further three readings were recorded at $2 \mathrm{~min}$ intervals, and the mean of all six readings taken. The radial pulse rate was manually recorded over a 1 min period. The individuals were categorised as normotensives \& prehypertensives. Known hypertensives \& students on antihypertensive management \& non consented students were excluded from the study.

RESULTS: The sample of 500 students was analysed by applying ANOVA logistic regression analysis. Out of a total of 500 students, there were 267(53.4\%) boys \& 233(46.6\%) girls.

277 students (55.4\%) fell in the prehypertensive range out of which $145(29 \%)$ students had a high SBP \& 132(26.4\%) had high DBP. Amongst the 227 students, 92(33.2\%) had both high SBP \& DBP out of which 93 (64.1\%) were boys \& 52 (35.9\%) were girls.

There was a family history of hypertension in one parent in 153 students $(30.6 \%)$ \& that of both parents in 30 students (6\%) in the entire study group out of which 67 (13.4\%) of them were prehypertensives. However there were no subjects who were hypertensive in our study.

Out of the 500 students, 66 boys (24.7\%) \& 93 (39.9\%) girls were overweight (BMI more than the normal range).

There was significant correlation between prehypertension \& a raised BMI with a $\mathrm{P}$ value less than 0.05 in boys but on the contrary, there was no significant correlation between the two in the girls (P value more than 0.05).

SPSS 2 verison was used for data analysis, Student t-test was used to calculate the Karl Pearson's correlation coefficient. 
DISCUSSION: Hypertension is a known risk factor for cardiovascular accidents well studied across the globe. Pre hypertension is a potential modifiable risk factor preceding hypertension. Physicians across the globe are found to have higher prevalence of metabolic syndrome than previously expected. There is an urgent need to estimate the risks among the healthcare professionals. From our analysis of nearly $55 \%$ of our students fell in the prehypertensive range which is more than the general population. Amongst the prehypertensives ( $n=277), 93(33.2 \%)$ of them had both elevated systolic \& diastolic blood pressures which puts them at a higher risk than those with only elevated systolic or diastolic BP. We hypothesize that the medical students undergo similar or more stress during their training period with little physical activity, altered food habits and recreational social habits like smoking \& alcohol might have accentuated our finding. All the students in our study group belonged to the same socioeconomic strata \& consumed the same kind of food.

Among the prehypertensives, we found a favourable outcome for girls ( $64 \%$ among boys and $36 \%$ among girls) probably due to the protective action of estrogen. The role of estrogen in hypertension is not clear as some data suggests otherwise (HRT in women). More data \& deeper insight into this possibility needs to be assessed. In our present study group 66 boys were categorized as overweight with a positive correlation with high blood pressure. Influence of gender in hypertension prevalence has been observed among men who showed higher prevalence of both systolic and diastolic hypertension in young age (11). In the present study analysis we have identified a previously underestimated subgroup of prehypertensives in concordance with the JNC-VII criteria, which needs special attention to avoid progression to hypertension and possible cardiovascular disease.

In our study group 183 students (36.6\%) had a positive family history of hypertension which accounts to more than one third of the study population. This obviously implies that a strong family history is an independent risk factor \& those students are prone to develop prehypertension prematurely. Thus tackling them should be our prime priority to prevent or delay future comorbidities.

The public health implication of this increased burden of at-risk people in our population requires serious consideration. It has been estimated that a $5 \mathrm{mmHg}$ reduction in systolic blood pressure in the population will produce a $14 \%$ reduction in the risk of stroke and a $9 \%$ reduction in the risk of coronary heart disease (12). The present study stresses the need to target this subgroup of prehypertensives more aggressively to prevent the epidemic of hypertension and its sequelae like coronary artery disease and chronic kidney disease. It has been shown that overweight status and increasing age are potential risks for future development of hypertension thus obesity management and lifestyle modifications are potential factors in the prevention of hypertension (1) and we stress the need to inculcate this in the early training period among the medical students to keep the health care fraternity in better shape. Prehypertension \& hypertension are also significant risk factors for the development of insulin resistance \& hence metabolic syndrome which is reported frequently in India. Presently pharmacological therapy has not been recommended to treat prehypertension except for those with other comorbid risk factors (13).

Strength of this study was a large group of medical students from a homogenous age and socioeconomic background. There is limited data among Indian literature in this population. Limitation of this study was absence of follow-up. 
CONCLUSION: We conclude that we have an alarming number of prehypertensive subgroup in the community which needs to be identified and informed of the future complications. Prehypertension is potentially modifiable with simple lifestyle modifications. The prevalence is higher among the healthcare providers than previously expected.

ACKNOWLEGDEMENTS: We deeply acknowledge Indian Council of Medical Research (ICMR), New Delhi, for funding this project in the form of Short Term Students Research Programme (STS) \& are grateful to all the participants who also made this possible.

\section{REFERENCES:}

1. Yadav S, Boddula R, Genitta G et al. Prevalence and risk factors of prehypertension and hypertension in an affluent north Indian Population. Indian J Med Res. 2008 Dec;128:712-20

2. King DE, Everett CJ, Mainous AG. Long term prognostic value of resting heart rate in subjects with prehypertension. Am J Hypertens. 2006 Aug;19(8):796-800

3. Ishikawa Y, Ishikawa J, Ishikawa S et al. Prehypertension and the risk for Cardiovascular disease in the Japanese general population: The Jichi Medical School Cohort Study. J Hypertens.2010 Aug;28(8):1630-37

4. Elliot WT, Black HR. Prehypertension. Nat Clin Pract Cardiovasc Med. 2007 Oct; $4(10): 538-48$

5. Israeli E, Korzets Z, Tekes Manona D et al.Blood pressure categories in adolescence predict development of hypertension in accordance with the European guidelines. Am J Hypertens. 2007 Jun;20(6):705-9

6. Tirosh A, Afek A, Rudich A et al. Progression of normotensive adolescents to hypertensive adults: A study of 26,980 teenagers. Hypertension. 2010 Aug;56(2):203-9

7. Israeli $\mathrm{E}$, Schochat $\mathrm{T}$, Korzets $\mathrm{Z}$ et al. Prehypertension and obesity in adolescents: $\mathrm{A}$ population study. Am J Hypertens. 2006 Jul;19(7):708-712

8. Gupta AK, McGlone M, Greenway FL, Johnson WD. Prehypertension in disease free adults: A marker for adverse cardiometabolic risk profile. Hypertens Res. 2010 Sep;33(9):905-10

9. Zhu H, Yan W, Ge D, Frank A, Gregory A. Cardiovascular characteristics in American Youth with prehypertension. Am J Hypertens. 2007 Oct;20(10):1051-57

10. Lee SJ, Lee KT, Lin KC et al. Prevalence of prehypertension \& associated risk factors in a rural Taiwanese adult population. Intl J Cardiol. 2010 Oct;144(2):269-73

11. Mathavan A, Chockalingam A, Chockalingam S, Bilchik B, Saini V. Madural Area Physicians Cardiovascular Health Evaluation Survey(MAPCHES)- an alarming status. Can J Cardiol. 2009 May;25(5):303-8

12. Gonzalez-Ortis M, Martinez-Abundez E, Hernadez-Salazar E, Robles-Cervantes JA. Obesity and dyslipidemia in primary care physicians. Acta Cardiol. 2008 Jun;63(3):331-4

13. Strachan MVJ, Walker BR in Nicholas A Boon, Nicki R Colledge, Brian R Walker, John A A Huner editors. Davidson's Principles and Practice of Medicine, $20^{\text {th }}$ edition: Elsevier publication;2006:766

14. Das SK, Sanyal K, Basu A. Study of urban community survey in India: growing trend of high prevalence of hypertension in a developing country. Int J Med Sci. 2005 Apr;2(2):70-78

15. Ferguson TS, Younger Novie OM, Tulloch-Reid MK et al. Prevalence of prehypertension $\&$ its relationship to risk factors for cardiovascular disease in Jamaica: Analysis from a cross sectional survey. BMC Cardiovascular Disorders. 2008 Aug;8:20

16. Zang Y, Lee ET, Devereux RB et al. Prehypertension, Diabetes and Cardiovascular Disease Risk in a Population-Based Sample: The Strong Heart Study. Hypertension. 2006; $47: 410-414$ 
RESULTS: WHOLE SAMPLE

\begin{tabular}{|l|l|l|l|l|}
\hline \multirow{2}{*}{ Variables } & \multicolumn{3}{|l|}{ SBP between 121 \& 139 } & \multicolumn{2}{l|}{ DBP between 81 \& 89 } \\
\cline { 2 - 5 } & $\begin{array}{l}\text { Pearson's } \\
\text { coefficient }\end{array}$ & p value & $\begin{array}{l}\text { Pearson's } \\
\text { coefficient }\end{array}$ & p value \\
\hline BMI \& SBP & 0.176 & $0.034(<0.05)$ & 0.315 & 0 \\
\hline BMI \& DBP & 0.129 & $0.123(>0.05)$ & 0.031 & 0.727 \\
\hline
\end{tabular}

CORRELATION BETWEEN TWO VARIABLES WITH REGARDS TO GENDER (WHOLE SAMPLE)

\begin{tabular}{|l|l|l|l|l|}
\hline Variables & \multicolumn{2}{|c|}{ Male } & \multicolumn{2}{c|}{ Female } \\
\cline { 2 - 5 } & $\begin{array}{l}\text { Pearson's } \\
\text { coefficient }\end{array}$ & p value & $\begin{array}{l}\text { Pearson's } \\
\text { coefficient }\end{array}$ & p value \\
\hline BMI \& SBP & 0.300 & $<0.0001$ & 0.310 & $<0.0001$ \\
\hline BMI \& DBP & 0.268 & $<0.0001$ & 0.216 & $<0.01$ \\
\hline
\end{tabular}

CORRELATION BETWEEN TWO VARIABLES WITH REGARDS TO HIGH BMI

\begin{tabular}{|l|l|l|l|l|}
\hline Variables & \multicolumn{2}{|c|}{ Male } & \multicolumn{2}{c|}{ Female } \\
\cline { 2 - 5 } & $\begin{array}{l}\text { Pearson's } \\
\text { coefficient }\end{array}$ & $p$ value & $\begin{array}{l}\text { Pearson's } \\
\text { coefficient }\end{array}$ & p value \\
\hline BMI \& SBP & 0.285 & $\begin{array}{l}<0.006 \\
(<0.01)\end{array}$ & 0.047 & $<0.710(<0.05)$ \\
\hline BMI \& DBP & 0.232 & $\begin{array}{l}<0.025 \\
(<0.05)\end{array}$ & 0.136 & $<0.3(<0.05)$ \\
\hline
\end{tabular}




\section{ORIGINAL ARTICLE}

\section{Scatter diagram with line of regression (linear)-BMI>23kg/sq.mt (n=145)}
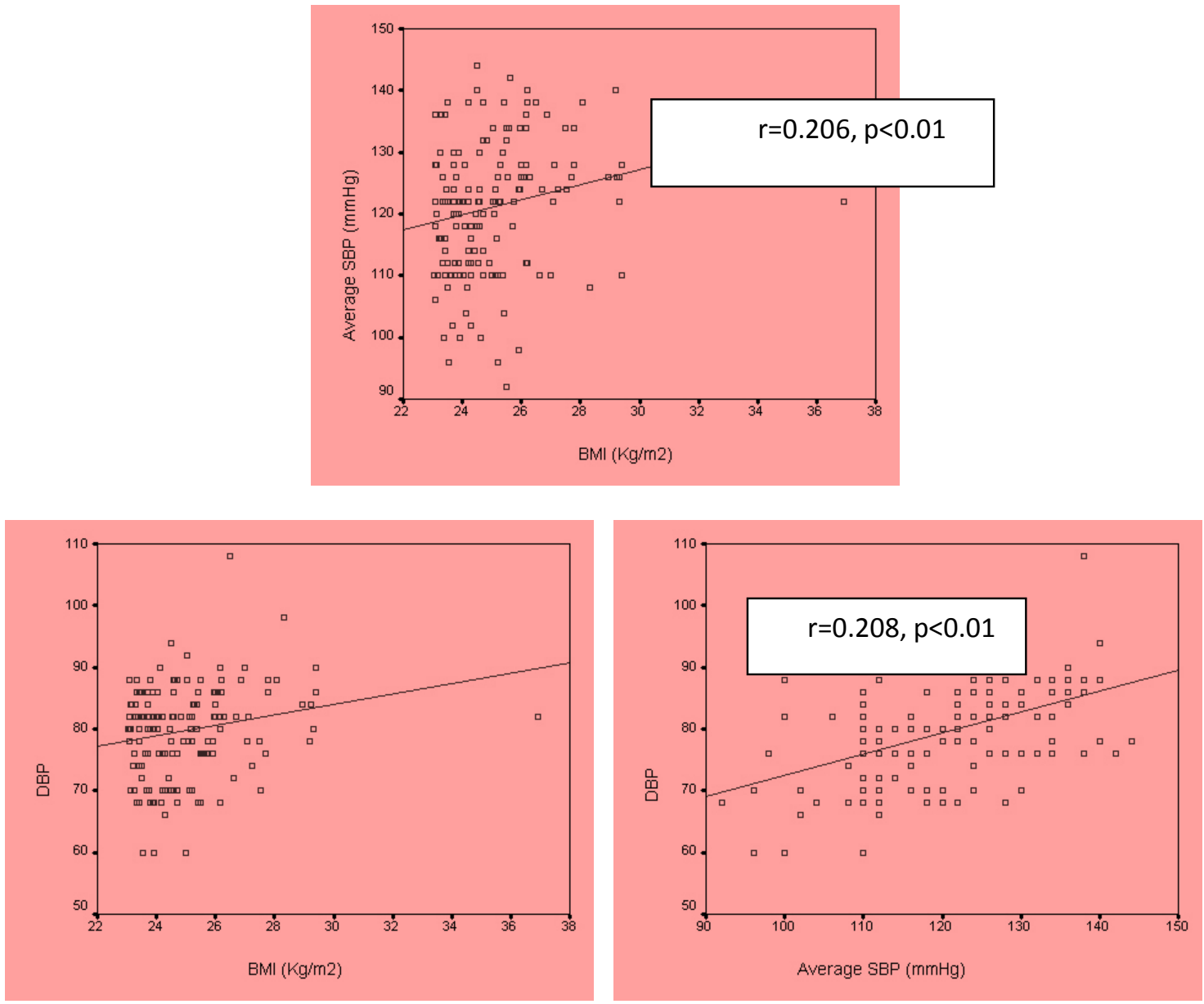

Bar-chart showing difference in male and female groups

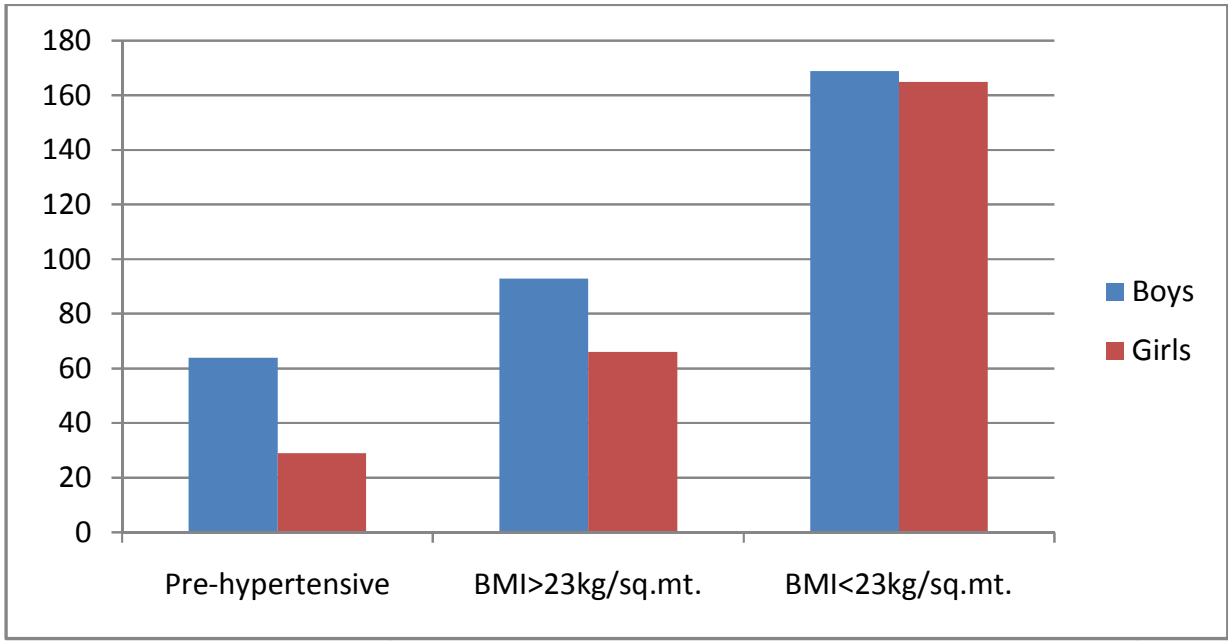

Data: there are 64 boys and 29 girls among pre-hypertensive. 93 males and 66 females are having $\mathrm{BMI}>23$ and 169 males and 165 females are having $\mathrm{BMI}<23$. 